\title{
Large Vulva Haematoma Following Spontaneous Vaginal Delivery: Successful Conservative Management in Enugu, South East Nigeria
}

\author{
Henry C. Nnaji, Theophilis 0. Nwankwo*, Uzochukwu U. Aniebue, Augustine 0. Asogwa \\ Departments of Obstetrics \& Gynaecology, University of Nigeria Teaching Hospital, Enugu, Nigeria \\ Email: ${ }^{\star}$ theonwankwo@gmail.com
}

How to cite this paper: Nnaji, H.C., Nwankwo, T.O., Aniebue, U.U. and Asogwa, A.O. (2020) Large Vulva Haematoma Following Spontaneous Vaginal Delivery: Successful Conservative Management in Enugu, South East Nigeria. Advances in Reproductive Sciences, 8, 31-35. https://doi.org/10.4236/arsci.2020.81003

Received: November 14, 2019

Accepted: December 30, 2019

Published: January 2, 2020

Copyright $\odot 2020$ by author(s) and Scientific Research Publishing Inc. This work is licensed under the Creative Commons Attribution International License (CC BY 4.0).

http://creativecommons.org/licenses/by/4.0/

(c) (i) Open Access

\begin{abstract}
Background: Vulva haematoma is an uncommon complication of childbirth that can cause maternal death if not properly managed. We present a case of large vulva haematoma managed conservatively with good outcome in UNTH Enugu. Clinical Presentation: This was a case of an unbooked 24 years old primiparous woman referred from a private hospital to UNTH, Enugu on account of left-sided vulva swelling of four hours duration following a spontaneous vaginal delivery of a live male baby that weighed 3.6 kilogrammes. She was given episiotomy which was repaired. Vaginal examination showed a swelling involving left labia majora and minora and extending to the perineal region and vagina. It measured $12 \mathrm{~cm} \times 10 \mathrm{~cm}$, firm and mildly tender. She was resuscitated with intravenous fluid, transfused with two units of blood and commenced on antibiotic and analgesic. The vulva haematoma was monitored and it remained the same size for two days, and then progressively regressed. She was discharged home on the 9th day. Conclusion: Conservative management of large vulva haematoma involving good counseling, correction of anaemia, institution of antibiotics, analgesic and close monitoring leads to effective resolution, reduced cost, scarring, pain and dyspareunia.
\end{abstract}

\section{Keywords}

Large Vulva Haematoma, Episiotomy, Conservative Management

\section{Introduction}

Vulva haematoma is an uncommon complication of childbirth with the potential of causing maternal morbidity and death if not properly managed. Vulva has a rich blood supply from the pudendal vessel. Improper haemostasis during repair 
of perineal tears or episiotomy wound or failure to take precaution while suturing the apex of the episiotomy may result in large vulva haematoma due to distensible nature of the vulva tissue. There are no consensus guidelines on the management of large vulva haematoma due to paucity of data. We present a case of large vulva haematoma managed conservatively with good outcome in University of Nigeria Teaching Hospital Enugu.

\section{Case Report}

This was a case of an unbooked 24 year old primiparous woman referred from a private hospital to University of Nigeria Teaching Hospital, Ituku Ozalla, Enugu on account of left sided vulva swelling. She had a spontaneous vaginal delivery of a live male baby that weighed 3.6 kilogrammes four hours prior to presentation. The labour was said to have progressed satisfactorily and she had episiotomy during second stage of labour, which was repaired following delivery. However about three hours later she complained of left vulva swelling and vulva pain. She was then referred to University of Nigeria Teaching Hospital for expert care. On presentation, she was pale with haemoglobin of $8 \mathrm{~g} / \mathrm{dl}$ and her pulse rate was 112 beats/minute. Vaginal examination showed a swelling involving left labia majora and minora and extending to the perineal region and vagina. It measured $12 \mathrm{~cm}$ $\times 10 \mathrm{~cm}$, firm and mildly tender. Figure 1 below shows the vulva haematoma on presentation. She was counselled on her condition and she opted for conservative management. She was immediately admitted and resuscitated with intravenous fluid. She was transfused with two units of blood and commenced on antibiotics and analgesics. Urethral catheter was passed to monitor fluid input output which was normal. The vulva haematoma was monitored and it remained same size for about 12 hours, and then progressively regressed. Serial haemoglobin done was within normal range. She was discharged home on the $9^{\text {th }}$ day in good clinical state and given 6 weeks appointment. At six weeks postnatal visit, she had no complaint. She has stopped draining lochia. She has resumed coital activity. Vaginal examination revealed normal vulva and vagina. Figure 2 below

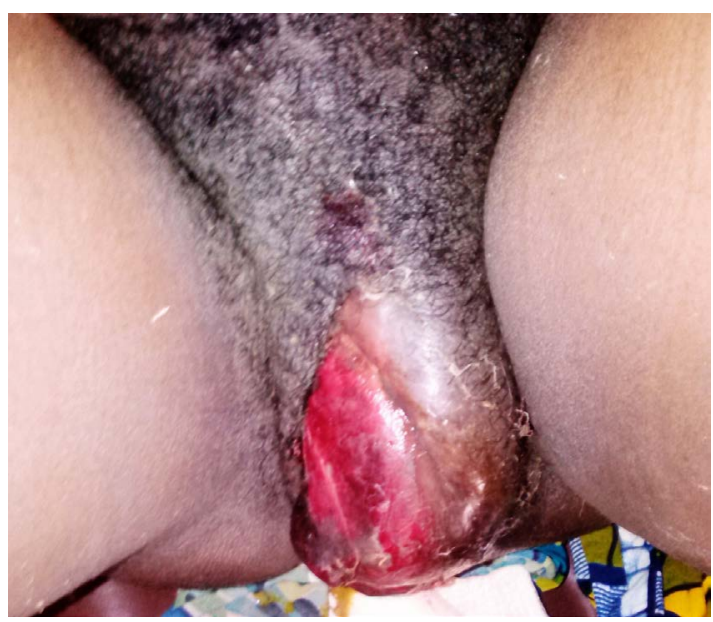

Figure 1. Patient's vulva on presentation. 


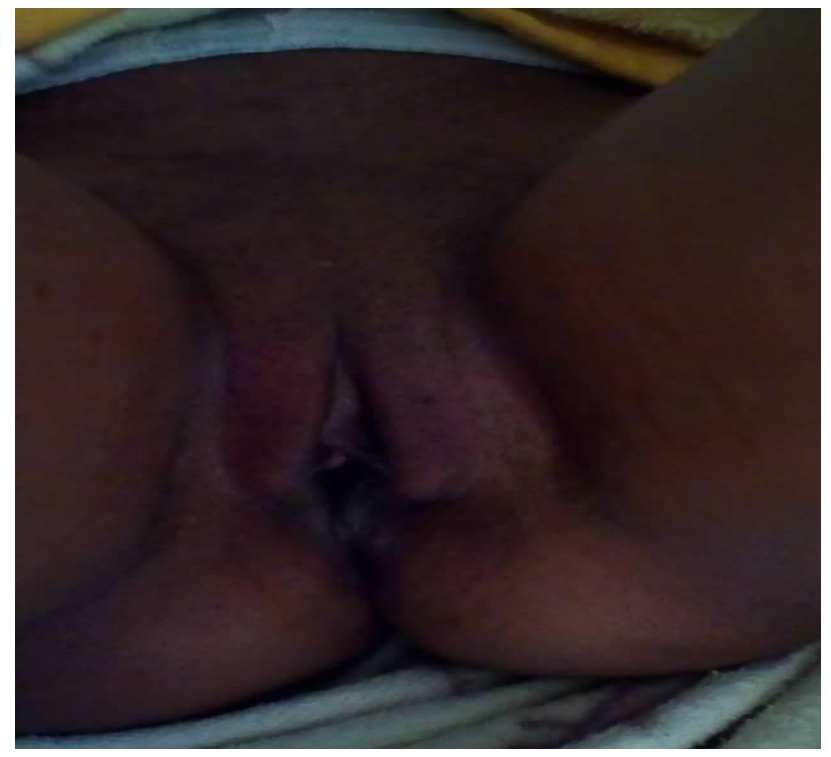

Figure 2. Patient's vulva on post natal presentation at 6 weeks.

shows the patient's vulva at six weeks post partum which was normal. Her baby was on exclusive breast feeding, adequately immunized for age, healthy and weighed $4.5 \mathrm{~kg}$. She was then discharged to family planning clinic.

\section{Discussion}

Traumatic postpartum vulva haematomas are uncommon complication of childbirth that can cause maternal morbidity and death if not properly managed. Incidence of 1:500 has been documented [1]. Risk factors for postpartum vulva haematoma include nulliparity, prolonged second stage, instrumental delivery, macrosomic babies, genital tract varicosity and younger maternal age. The index patient was nulliparous and 24 years. Most often it results following repair of episiotomies and may become large enough to cause haemodynamic instability [2]. Traumatic non-obstetric vulva haematoma are rare but can also cause death if not promptly treated [3]. Vulva haematoma usually results from injury to the labial branch of internal pudendal artery which is located in the superficial fascia of the anterior and posterior pelvic triangle. Vulva haematoma can be divided into vulval and pelvic types, depending on its relation to the levator ani. It can also be spontaneous or traumatic and the traumatic type can results from both obstetric and non-obstetric causes.

There are no consensus statement or best practice guideline on the modality for management of post-partum vulva haematoma due to paucity of publication. Conservative management has been suggested in the management of small non-expanding vulva haematoma $(<5 \mathrm{~cm})$ and haematoma above the levator ani muscle (supra levator vulva haematoma) [4]. However large vulva haematomas have also been suggested to be best managed with surgical evacuation and primary closure [5]. Arterial Embolization for large vulva haematoma is also a treatment method for patient that is unstable for surgery [5] [6] but the facilities 
are not usually available in a low resource setting like ours. In respect to cost effective treatment, there is need to buttress the effectiveness of conservative management of large vulva haematoma when observed not to be expanding. Hence the first line of treatment for large vulva haematoma may be to observe the patient while she is being resuscitated. Based on the observation, patient will then be properly counselled on the management options and allowed to make an informed consent. This modality of management was applied in the index patient and the large vulva haematoma was observed for 12 hours and was found not to be increasing in size. She consented to conservative management which was offered to her and it resulted in reduced treatment cost. She had no vaginal scarring and coital pain thereby stabilizing her family. She also reunited with her baby immediately after admission for conservative management. This modality of conservative management for large vulva haematoma has been earlier documented by Papoutsis et al. in management of a 40 year old woman with large vulva haematoma of traumatic origin at University of Michigan Hospital [7]. The outcome of their management was reported to be good and cost effective just like the present study. However, the size of the haematoma was less than that of the present study and they also advised the patient to perform warm soaks to improve local circulation and reabsorption of the haematoma which was not done in the present study. However, surgical evacuation was the modality applied by Alcalde et al. in the management of a non obstetric traumatic vulva haematoma of about $10 \times 5 \mathrm{~cm}$ in a 44 year old Caucasian woman [8]. The patient has an accelerated recovery and was discharged within 24 hours. However she never presented for any appointment which may be due to lack of satisfaction and possible huge surgery cost paid by the patient. This underscores the need for conservative management which obviates this surgical cost.

\section{Conclusion}

Conservative management of large vulva haematoma may be a better management option in our environment as it leads to effective resolution of the symptoms while obviating the risk of anaesthesia, and surgery.

\section{Patient Consent}

Both oral and written consent were obtained from this patient for publication of this case report.

\section{Conflicts of Interest}

There was no conflict of interest regarding the publication of this case.

\section{References}

[1] Morgan, D., Chan, N. and Clark, C.A. (1999) Vulva Perineal Haematoma in the Immediate Postpartum Period and Their Management. Australian and New Zealand Journal of Obstetrics and Gynaecology, 39, 223-227. https://doi.org/10.1111/j.1479-828X.1999.tb03378.x 
[2] Ernest, A. and Knapp, G. (2015) Severe Traumatic Vulva Hematoma in Teenage Girl. Clinical Case Reports, 3, 975-978. https://doi.org/10.1002/ccr3.395

[3] Taingson, M.C., Adze, J.A., Bature, S.B., Durosinlorun, A.M., Celeb, M. and Amina, A. (2018) Haematoma of the Labia Minora Following Consensual Sexual Intercourse. Sahel Medical Journal, 21, 52-53. https://doi.org/10.4103/smj.smj_33_16

[4] Awoleke, J.O. and Ipinnimo, O.M. (2017) Vulvavaginal Infralevotor Haematoma Mimicking the Second Stage of Labour. Case Reports in Obstetrics and Gynecology, 2017, Article ID: 8062793. https://doi.org/10.1155/2017/8062793

[5] Hwang, K.R., Kim, S.A., Kwon, J.E., Jeon, H.W., Choi, J.E. and So, Y.H. (2014) A Case of Vulvar Hematoma with Rupture of Pseudoaneurysm of Pudendal Artery. Obstetrics \& Gynecology Science, 57, 168-171.

https://doi.org/10.5468/ogs.2014.57.2.168

[6] Kunishima, K., Takao, H., Kato, S. and Ohtomo, K. (2008) Transarterial Embolization of a Nonpuerperal Traumatic Vulva Haematoma. Radiation Medicine, 26, 168. https://doi.org/10.1007/s11604-007-0208-5

[7] Papoutsis, D. and Haefner, H.K. (2017) Large Vulva Haematoma of Traumatic Origin. Journal of Clinical and Diagnostic Research, 11, 1-2.

https://doi.org/10.7860/JCDR/2017/30104.10542

[8] Alcalde, M.V.L., Hernandez, E.H., Alfonso, S.B. and Sanchez, M.J.D. (2019) Non Obstetric Traumatic Vulva Haematoma: Conservative or Surgical Approach? A Case Report. Case Reports in Women's Health, 22, Article ID: e00109. https://doi.org/10.1016/j.crwh.2019.e00109 